\title{
Urdimento
}

Revista de Estudos em Artes Cênicas

E-ISSN: 2358.6958

\section{Arte como potência de si, a peça-conferência e o ator-epistemólogo}

\author{
Djalma Thürler
}

Duda Woyda

Mariana Moreno

\section{Para citar este artigo:}

THÜRLER, Djalma; WOYDA, Duda; MORENO, Mariana. Arte como potência de si, a peça-conferência e 0 atorepistemólogo. Urdimento, Florianópolis, v. 2, n. 38, ago./set. 2020.

DOI: http:/dx.doi.org/10.5965/14145731023820200031

Este artigo passou peloPlagiarism Detection Software | iThenticate 
Arte como potência de si, a peça-conferência e o ator-epistemólogo

Djalma Thürler ${ }^{1}$

Duda Woyda²

Mariana Moreno ${ }^{3}$

\begin{abstract}
Resumo
Nos últimos anos, a peça-conferência surgiu como um formato importante na prática do teatro contemporâneo. A partir de um processo genealógico que anuncia um possível lastro de identificação e reconhecimento, os autores exploram em recentes produções teatrais elementos e características que configuram essa prática teatral híbrida que incorpora elementos espaciais e materiais tanto da palestra acadêmica quanto da performance artística e sugerem a presença de um novo ator, o ator-epistemólogo.
\end{abstract}

Palavras-chave: Peça-conferência. Teatro contemporâneo. Teoria queer. Decolonialidade. Ator-epistemólogo.

Art as power of self, the lecture-performance and the epistemologist-actor

\begin{abstract}
In recent years, the lecture-performance has emerged as a crucial format in the practice of contemporary theater. From a genealogical process that announces a possible identification and recognition coverage, the authors explore in recent theatrical production elements and distinctiveness that compose this hybrid theatrical practice, which absorb spatial and material elements of both the academic lecture as well the artistic performance and from that, we have the presence of a new type of the actor: the epistemologist-actor.
\end{abstract}

Keywords: Lecture-performance. Contemporary theater. Queer theory. Decoloniality. Epistemologist-actor.

\footnotetext{
1 Prof. Dr. Programa Multidisciplinar de Pós-Graduação em Cultura e Sociedade e Professor Associado II do Instituto de Humanidades, Artes e Ciências (IHAC) da Universidade Federal da Bahia.(UFBA). djalmathurler@ufba.br

${ }^{2}$ Doutorando em Cultura e Sociedade na Universidade Federal da Bahia e investigador da ATeliê voadOR Teatro (UFBA). dudawoyda@gmail.com

${ }^{3}$ Mestranda em Cultura e Sociedade na Universidade Federal da Bahia e investigadora da ATeliê voadOR Teatro (UFBA). mariana.bauproducoes@gmail.com
} 


\section{A arte e o cistema}

Nosso primeiro objetivo vai em direção a desvendar a primeira parte do título deste artigo: "A arte como potência de si”. Partimos, então, para o nosso entendimento de Arte, ou como a temos pensado nos últimos 10 anos, parafraseando um trecho do texto Cabaré Vibrátil (2019), quando um dos atores afirma:

Quando alguém perguntar 'pra que é que serve a arte', responda de maneira agressiva, porque quem perguntou quis ser irônico e cáustico. A arte serve para causar dano à estupidez, para transformar a estupidez em algo vergonhoso. (Thürler, 2019, s/p).

Nessa direção, confiamos nosso caminho de entendimento sobre Arte a Deleuze e Guattari (1992). Esses autores nos convenceram que a arte não seria capaz apenas de representar subjetividades, mas também de produzi-las. A arte nos permitiria criar novos modos de vida, outros discursos sobre o mundo, as pessoas, seus desejos. As formulações desses autores, então, nos permitem entender a Arte enquanto possibilidade de ação política que opera como uma prática micropolítica reativa capaz de mudar e ampliar subjetividades. Poderíamos, ainda, contemplar esse entendimento com Rancière, para quem “a arte é política enquanto os espaços e os tempos que ela recorta e as formas de ocupação desses tempos e espaços que ela determina interferem na definição de uma comunidade política." (Rancière, 2014, s/p).

Depois rastreamos a ideia de potência e identificamos aquela associada à "vontade de potência”, de Nietzsche, que argumenta que o homem não pode e não quer apenas conservar-se ou adaptar-se para sobreviver, isso só poderia ser o desejo de uma pessoa doente, diria ele; uma pessoa saudável, ao contrário, quer algo mais, expandir-se, dominar, criar valores, dar sentidos próprios, superar-se, juntar-se a outras e tornar-se maior, fazer-se mais forte, constranger outras forças, assimilá-las. Isto significa criar suas próprias condições de potência, efetivar-se no encontro com outras forças. A pessoa dotada de vontade de potência, tem vontade de poder alcançar o estado de permanente desejo de vida, 
é aquela que pode dilacerar, destruir, modificar todos os conceitos, buscar sempre mais, sempre o diferente, sempre a mutação.

E por último, associamos essa ideia de potência ao pronome oblíquo átono si, que só é utilizado quando a voz do verbo é reflexiva, quando o sujeito pratica e sofre a ação verbal. E só se considera correto entre nós, usuários da Língua Portuguesa, o uso desse pronome como reflexivo da terceira pessoa. Então o título não fala de uma potência de mim, mas do outro, essa alteridade que é definida politicamente em oposição a um sujeito hegemônico, detentor do poder de auto representar-se e representar a diferença, enfim, o outro, aquele defenestrado do regime colonial-capitalístico (Rolnik, 2018, p.103), ou seja, do cistema, que estabelece preceitos em torno do

homem branco, heterossexual, de classe média urbana e cristão, e essa passa a ser a referência que não precisa ser nomeada. Serão os 'outros' sujeitos sociais que se tornarão 'marcados', que se definirão e serão denominados a partir dessa referência. (Louro, 2010, p.15-16).

A potência de si seria, então, o contrário da potência cis, e aqui pensamos com Viviane Vergueiro, que entende "a cisgeneridade como um posicionamento, uma perspectiva subjetiva que é tida como natural, como essencial, como padrão" (Guzmán, 2014, p.15), ou seja, os "corpos adequados a uma normatividade cisgênera ou a uma cisnormatividade, [...] são existências colonizadas, e aqui tomando colonização na sua acepção mais ampla, de colonização cultural, do saber, [do poder] colonização existencial dentro de um sistema, um sistemamundo usando o termo do Quijano, e essas cis-normatividades atuando nas identidades de gênero não normativas”. (Guzmán, 2014, p.15).

A potência do outro performada no palco ilustra o teatro como um espaço do torna-se (Kilomba, 2019), uma operação de transformação do "objeto” - que o projeto colonial determinou - em “sujeito”. Segundo bel hooks (1989, p. 42), aquele que tem "o direito de definir suas próprias realidades, estabelecer suas próprias identidades, de nomear suas histórias” (apud Kilomba, 2019, p. 28), o palco que 
organiza experiências outras capazes de gerar novos modos de existências, novos modos de agir, de sentir, de dizer o mundo.

Após esse quadro, concentramo-nos sobre algumas peças de teatro que apresentam um formato importante na prática do teatro contemporâneo, considerando que os efeitos produzidos por esses objetos estéticos refletem impactos em forma de políticas de subjetivação que geram linhas de fuga responsáveis por escapar da normatividade dos dispositivos cênicos mais tradicionais.

Falamos das peças-conferências, que incorporam elementos tanto da palestra acadêmica quanto da performance artística, funcionam simultaneamente como meta-leitoras e como meta-performativas e, como tal, desafiam ideias estabelecidas sobre a produção de conhecimento e significado em cada uma das formas a que se referem. Vamos tentar discutir, a partir de sua genealogia, a performance da palestra analisando sua contribuição em diferentes contextos para o fortalecimento de uma arte política, implicada em questões de desaprendizagem (Thürler, 2018), que inclui uma análise de outros contextos que a performance da palestra estabelece e participa: contextos de fazer e assistir.

\section{Peça-conferência: por uma outra genealogia}

As peças das quais falaremos estariam enquadradas num formato que temos chamado de palestra-performativa, palestra-performance, peça-conferência, aula-performance ou aula-conferência. Embora uma recente genealogia tenha sido elaborada por Marco Catalão em Uma genealogia para a palestraperformance, em 2017, então como fruto de projeto de pós-doutorado, intitulado Teatro Virtual, pensamos, conforme apontou Michel Foucault (1993), que a genealogia compreende que não há na origem dos acontecimentos uma identidade originária preservada, mas há acaso, paixões, disparates, descreve as forças históricas que tornaram possíveis as culturas e os modos de vida em seu confronto. Dessa forma, 
[...] não se trata de forma alguma de desqualificar o especulativo para the opor, na forma de um cientificismo qualquer, o rigor dos conhecimentos bem estabelecidos. Portanto, não é um empirismo que perpassa o projeto genealógico; não é tampouco um positivismo, no sentido comum do termo, que o segue. Trata-se, na verdade, de fazer que intervenham saberes locais, descontínuos, desqualificados, não legitimados, contra a instância teórica unitária que pretenderia filtrá-los, hierarquizá-los, ordená-los em nome de um conhecimento verdadeiro, em nome dos direitos de uma ciência que seria possuída por alguns. As genealogias não são, portanto, retornos positivistas a uma forma de ciência mais atenta ou mais exata. As genealogias são, muito exatamente, anticiências. (Foucault, 1999, p.13-14).

Então, esse texto em seu método genealógico, provoca uma contra história à história pensada por Catalão (2017), se nos atentarmos para a sua genealogia da palestra-performance, através

da referência a alguns antecedentes óbvios, como as ações de John Cage, Robert Morris e Joseph Beuys, e outros menos evidentes, como alguns contos de Jorge Luís Borges e algumas exposições de pintores como Gustavo Courbet. (Catalão, 2017, p.5).

Trilhando outras pistas, para nós, a modalidade de peça-conferência ${ }^{4}$, como a entendemos, nos remete a 1997, quando Denis Guénoun fez sua estreia mundial no Festival de Avignon, com o texto Lettreau directeur du théâtre ${ }^{5}$. No Brasil, essa mesma peça, intitulada Carta Aberta, com tradução, adaptação e direção de Fernando Kinas, estreou um ano depois, em setembro de 1998 no Teatro Guairinha (Paraná) pretendendo ser "uma reflexão encenada que utiliza os recursos desenvolvidos pelo próprio teatro" (Folha de São Paulo, 2000, s/p), uma experiência cênica que fala sobre o teatro. Trata-se, neste espetáculo, de uma reflexão sobre a condição da atividade teatral no mundo contemporâneo, abordando seus principais aspectos como a relação com o público, subvenções, dramaturgia, condições de produção, definição etimológica, formação do ator e o papel da imprensa. Mesmo classificado como teatro, a principal característica de

\footnotetext{
${ }^{4}$ Daqui por diante, dentre as inúmeras possiblidades de denominação, utilizaremos o termo peça-conferência.

${ }^{5}$ No Brasil a peça foi traduzida por Carta ao diretor do teatro ou ainda por Carta aberta.
} 
"Carta Aberta" era a qualidade das argumentações a partir de uma abordagem filosófico-social dos temas discutidos, uma encenação da fala. (Ryngaert, 2013).

As relações entre a Filosofia e o Teatro, aliás, foram tratadas por María J. Ortega Máñez, em La idea em escena: Platón, San Agustín y Spinoza por Denis Guénoun (2019). Nesse texto, ao perguntar se é possível que o teatro pense e a filosofia teatralize, Máñez aponta para, talvez, o principal eixo daquilo que estamos pensando sobre a peça-conferência, no seu afã de se distanciar do teatro diegético, que é o efeito performativo do discurso crítico. Sobre essa característica, em Afinação I, peça que abordaremos ainda neste texto, sua realizadora, Georgette Fadel assume sobre seu trabalho, que "[o trabalho] é de uma crueza e simplicidade cultivadas deixando todo o protagonismo para os movimentos do pensamento." (Fadel, 2017c, s/p).

Caminho semelhante trilhou Product of Circumstances, "palestrademonstração" do coreógrafo francês Xavier Le Roy, em 1999. Usando seu próprio corpo para montar uma peça-conferência, Le Roy traçou sua trajetória pessoal, desde o estudante de biologia molecular, doutorando, até o bailarino e coreógrafo, imaginando novos modos de comunicação verbal e não-verbal, fazendo a ponte entre a ciência e a arte da performance com seu próprio corpo. Le Roy descreve isso na performance:

Comecei a ter aulas de dança duas vezes por semana ao mesmo tempo em que comecei a trabalhar na minha tese para meu doutorado em biologia molecular e celular. Como trabalho como dançarino ou coreógrafo, muitas vezes sou apresentado como um dançarino atípico ou como um dançarino biologista molecular... Biografia como teoria. Uma conferência autobiográfica se tornando uma performance. Meu corpo como matéria-prima da organização social e cultural e como uma prática de necessidade crítica. ${ }^{6}$ (Le Roy, 2016, s/p).

${ }^{6}$ I began to take two dance classes a week at the same time that I started to work on my thesis for my PhD in molecular and cellular biology ... Since I work as a dancer or choreographer I am very often presented as an atypical dancer or as a dancer molecular biologist ... Biography as theory. An autobiographical conference becoming a performance. My body as raw material of social and cultural organization and as the practice of critical necessity. (Le Roy, 2016, s/p). (Tradução nossa) 
Product of Circumstances, enquanto lecture-performance, "era sobre a construção de um corpo contaminado em suas relações em nível histórico, social, cultural e biológico" (Le Roy, 1999, s/p), ou seja, Le Roy compreende que a construção do corpo se dá por um processo diversificado, permanente e cultural, revelando o caráter fictício da noção de sujeito. No fundo Le Roy, afinado com Nietzsche, transforma o próprio significado da noção de sujeito, libertando o indivíduo do espartilho rígido da identidade, abrindo possibilidades às experiências do devir, das diferentes formas de estar além dos pontos de referência canônicos e imutáveis, categoricamente normativos. E faz como se estivesse dando uma palestra, descrevendo seu próprio processo em se tornar um bailarino, construindo uma narrativa que incluiu sua relação com diferentes espaços, desde o laboratório, até o estúdio de dança, bem como o espaço público.

Desta forma, o artista-professor conectou o trabalho de dança e coreografia com o da pesquisa biológica, considerando ambos como formas de entender o corpo em sua relação contígua com o social, portanto sujeito a regimes de normatividades que asseguram certa normalidade na vida social, mas, também, o corpo como recurso e local para experimentação, um fio condutor híbrido entre o trabalho artístico e a prática científica.

Figura 1 - Xavier Le Roy. Product of Circumstances

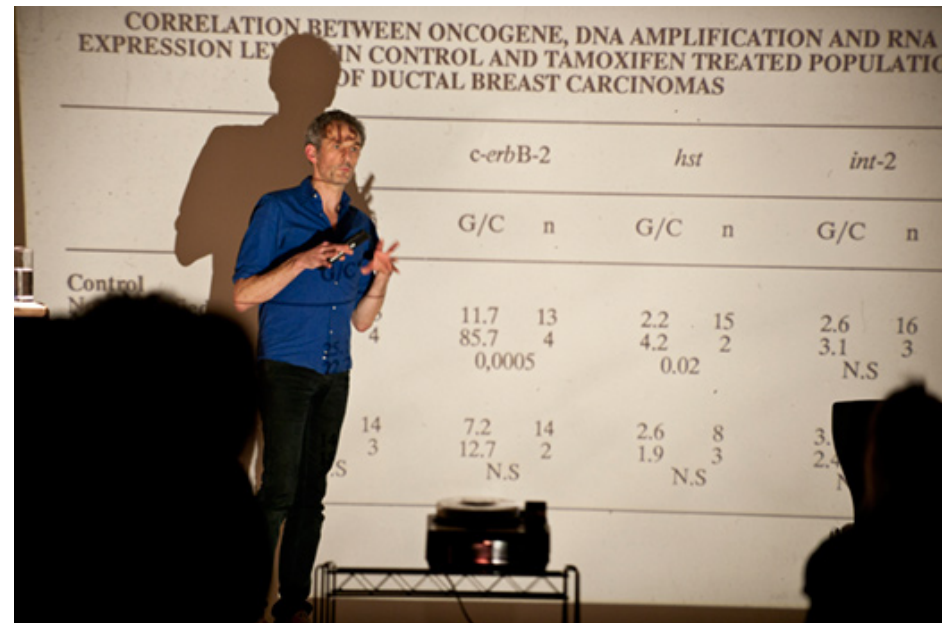

Fonte: http://www.chronicles-of-work.de/Cow1/le_roy.html. Acesso em: 03 jul. 2020.

${ }^{7}$ was about a contaminated body in its weavings of historical, social, cultural and biological levels. (Tradução nossa) 
Tanto Product of Circumstances como Lettreau directeur du théâtre, ou ainda The Art of Laughter, essa de Jos Houben, propõem uma negociação contínua entre o intérprete e o público, o que parece ser outra característica desse gênero: a próxima e intensa convivência entre o público e o intérprete. Outras características podem ser extraídas da primeira rubrica do texto de Le Roy, quando diz que

essa performance foi originalmente apresentada em um Teatro (Podewil Berlin) e pode ser exibida em qualquer formato cênico que permita ter uma audiência / plateia na frente do palco e uma tela para projeção de slides. (Teatros, salas de conferência e etc). A iluminação deve ser, na medida do possível, a mesma, tanto no palco como na área do público. Para a projeção dos slides ela deve perder a intensidade, mas nunca com blackout total. A iluminação está presente no começo e no fim da performance e nunca se apaga. A depender do espaço você pode usar um microfone, uma mesa de conferência, um projeto de slides, uma cadeira, travesseiro ou qualquer outro objeto de cena que você julgue necessário usar na performance. O texto está escrito em inglês correspondendo à minha habilidade nesse idioma. Faz parte da apresentação e deve ser lido da forma mais clara possível. A performance deve, tanto quanto possível, apresentar cada elemento como fato, tentando não enfatizar nenhum dos aspectos. Procure atuar sem ironia, sarcasmo, romantismo ou qualquer efeito que possa transformar os fatos. O desempenho de cada elemento deve estar o mais próximo possível do fato. Todo texto que não esteja em itálico deve ser dito ou lido. Os textos em negrito e itálico são instruções de movimento. ${ }^{8}$ (Le Roy, 1999, s/p).

Além da questão espacial entre artista e público, chama atenção também a adequação do espaço. Vejam que, embora pensada originalmente para ser apresentada em um teatro formal - o Podewil Berlin -, Le Roy sugere que a peça possa ser apresentada em qualquer espaço, em salas e auditórios diversificados, bastando que permita que o público, de maneira frontal, à italiana, possa

${ }^{8}$ this performance was originally presented in a theatre [Podewil Berlin] and can be presented in any situation allowing an audience in front of a stage and a screen for slide projection [theatres, conference rooms, and so on]. The light should be, to the degree possible, the same on stage and in the audience space. The intensity should go down for slide projection but never be black. The light is there at the beginning and at the end of the performance and never goes off. Depending on the space, you might use a microphone, a conference desk, a slide projector, a chair, a pillow, or any other props you want to transform the performance. The text is written in English correspondent to my ability in this language; it is part of the presentation and should be read as clearly as possible. The performance should, as much as possible, present each element as a matter of fact, trying not to emphasize any of the aspects. Try to perform without irony, sarcasm, romanticism, or any affect that could transform the facts. The performance of each element should stay as close as possible to fact. Every text that is not italicized should be said or read. The texts in bold and italic are instructions for movements. (Le Roy, 1999, s/p). (Tradução nossa) 
acompanhar a projeção de slides. Vale acrescentar, sobre essa disposição frontal, o que dissera Jean-Jacques Roubine, para quem

não é necessário, no fundo, rejeitar a arquitetura italiana. Basta fazê-la trabalhar, por assim dizer, no sentido contrário. Ajudando a teatralidade a exibir-se assumidamente, em vez de recalcá-la. Mostrando os meios de produção do espetáculo, equipamentos elétricos, instrumentos musicais, etc. em vez de dar-se tanto trabalho para torná-los invisíveis [...] tudo isso se torna a própria base do teatro épico: o espectador brechtiano deve ver a distância. Deve conservar a cabeça fria frente a um espetáculo que não pretende mais substituir a realidade. Deve estar em condições de exercer suas faculdades de surpresa, de julgamento crítico. (Roubine, 1998, p.9192).

Mariana Lima, atriz de Cérebro_Coração, da qual falaremos mais adiante, reforça essa característica do espaço da peça-conferência: "Não me interessa fazer espetáculo para uma bolha de gente, feita de pares e algoritmos. Como fazer para que a massa fora da bolha vá ao teatro e se interesse? Penso que ir até eles pode ajudar a responder essa pergunta." (Lima, 2018, s/p).

Essa desespetacularização que a peça-conferência infere sobre si, também é notada em referência aos recursos de iluminação, quando a rubrica de Product of Circumstances indica que a luz da cena deve ser, na medida do possível, a mesma do espaço do público, não fazendo diferença entre os espaços da realidade (plateia) e ficção (palco), inclusive quando evita o BO (black-out), técnica que permite a transformação da cena às escuras, afinal, em uma encenação

nesse jogo de apagar e acender, cada black-out traz consigo uma surpresa. Uma vez que o espectador identifica a falta de unidade tanto narrativa quanto temática entre as cenas, sua expectativa é alterada. Isso, por sua vez, transforma a presença da escuridão e o valor dramatúrgico do black-out. (Ferrer, 2015, p. 65).

Ainda chamam atenção nessa rubrica inicial, dois aspectos. Um deles tem a ver com a atuação do intérprete, este deveria tentar atuar sem qualquer efeito que possa transformar os fatos, sem ironia, sarcasmo ou romantismo. Percebe-se aqui uma característica notada em todas as peças que compõem o escopo deste artigo, 
a negação da personagem (ou a diluição de seus contornos) e o consequente questionamento do procedimento fabular,

se a personagem é um dos principais suportes da ficção teatral, ou, em outras palavras, se a fabula e o regime ficcional que ela engendra repousam, em grande medida, na constituição de personagens com alguma identidade e estabilidade, é lógico supor que os movimentos de negação ou enfraquecimento da personagem produzem, em uma espécie de efeito cascata, o questionamento do procedimento fabular ("contar uma história”) e, portanto, da própria ficção. (Kinas, 2010, p. 175).

A indicação de que se deva ficar o mais próximo possível dos fatos, revela procedimento caro ao gênero em questão, uma peça-conferência seria, concordando com Kinas (2010), mais uma experiência de desorganização das regras do jogo teatral diretamente relacionadas à construção das personagens. Nesse sentido, "assim como o ator não mais deve iludir o público mostrando que se trata de uma personagem fictícia no palco e não dele, ator, não deve também simular que o que está acontecendo no palco não foi ensaiado”. (Brecht, 1967, p. 204).

Voltando à rubrica do texto de Le Roy, o outro aspecto que gostaríamos de destacar é a indicação de que em sua dramaturgia, todo texto que não esteja em itálico deve ser dito ou lido e que os textos em negrito e itálico são instruções de movimentos. Vejam no fragmento:

Boa noite, senhoras e senhores. Eu farei essa performance em Inglês. Se vocês tiverem qualquer pergunta depois, terei prazer em responder.

O nome dessa performance é "O produto das circunstâncias".

Em 1987 eu comecei a trabalhar na minha tese de doutorado em biologia molecular e cellular, ao mesmo tempo em que comecei a ter aulas de dança duas vezes por semana.

Terminei meu mestrado e recebi uma bolsa de estudos do governo Francês para escrever minha tese. No mesmo ano eu fui aceito para trabalhar em um laboratório especializado na pequisa de câncer de mama e hormônios. Além disso, comecei a assistir várias apresentações de dança durante os festivais de verão no sul da França onde eu vivia. Ainda no mesmo ano, o doloroso fim de um relacionamento amoroso de três anos.

Eu ainda jogava basquete com frequência e meu corpo necessitava de alongamento.

1. Eu deixo o papel e o microfone, dou três passos para o lado. Faço um exercício de alongamento, baixando meu corpo / torso, tentando alcançar 


\begin{abstract}
o solo com minhas mãos com 20 movimentos leves. Minhas mãos não chegam perto do chão, ficando a 20cm do mesmo, como era em 1987. Depois eu retorno para o microfone.

Pode ligar o projetor de slides e mudar a luz?

Obrigado.

O título da tese que eu apresentei em outubro de 1990 era

SLIDE \# 1: título da tese.

ESTUDO DA EXPRESSÃO DE GENES ONCOGÊNIOS E REGULAÇÃO HORMONAL EM CÂNCER DE MAMA UTILIZANDO HIBRIDIZAÇÃO IN SITU QUANTITATIVA. ${ }^{9}$ (h.i.s) (Le Roy, 1999, s/p).
\end{abstract}

Observando as orientações através do excerto, podemos destacar características importantes que ajudam a delinear mais elementos de uma peça-conferência. Percebam que, no texto, a passagem em itálico-negrito faz uma indicação de movimentação - deixar papel e microfone, dar três passos de lado etc. e, logo a seguir o ator volta ao microfone e fala: "Pode ligar o projetor de slides e mudar a luz? Obrigado" (Le Roy, 1999, s/p). Esse pedido ao técnico que acompanha a aula, essa quebra de ilusão, essa revelação evidencia "que o trabalho dos atores e atrizes em cena não era mais compatível com o velho modelo do faz de conta, da encarnação de um papel ou da identificação" (Kinas, 2010, p. 180), ou ainda, com o próprio Kinas, esse abandono da personagem forma par "com a recusa da fábula, dramática ou épica, e o questionamento da primazia da representação" (Kinas, 2010, p. 181). A essa altura cabe perguntar quem está em cena? Quem não está em cena? Ao tentar responder sobre

\footnotetext{
${ }^{9}$ Good evening, ladies and gentlemen. I will do this performance in English; if you have questions afterwards I will be glad to answer them.

The title of this performance is "Product of Circumstances"

In 1987 I started work on my thesis for my PhD in molecular and cellular biology, and at the same time I began to take two dance classes a week.

I finished my master's degree and received a scholarship from the French government to write my thesis. The same year, I was admitted to work in a laboratory specializing in research on breast cancer and hormones. Also, I started to see a lot of dance performances during the summer festivals in the south of France where I lived. The same year was the painful ending of a 3 years long love relationship.

I was still playing a lot of basketball and my body was trying to get some stretch.
}

1. I leave paper and microphone, go three steps on the side. I do a stretching exercise, bending my torso over and trying to reach the floor with my hands in 20 light bounces. My hands don't get closer than $20 \mathrm{~cm}$ from the floor, like it was in 1987. Then I go back to the microphone.

Can you please turn on the slide projector and change the lights. Thank you.

The title of the thesis I presented in October 1990 was

SLIDE \# 1: title thesis

STUDY OF ONCOGENES EXPRESSION AND HORMONAL REGULATION IN BREAST CANCER USING

QUANTITATIVE IN SITU HYBRIDIZATION (h.i.s) (Le Roy, 1999, s/p). (Tradução nossa) 
esse "eclipse da identidade da personagem." (Sarrazac, 2006, p. 359), nos associamos a Ryngaert, para pensar que

é ali que o personagem se redefine e talvez se reconstrua, notadamente na distância entre a voz que fala e os discursos que ela pronuncia, na dialética, cada vez mais complexa, entre uma identidade que vem a faltar e as palavras de origens diversas, no domínio de um teatro que, se não é mais narrativo, participa do comentário, da autobiografia, da repetição, do fluxo de vozes que se cruzam na encenação da palavra. (Ryngaert, 2008 , p. 114).

Talvez valha a pena falar sobre The believers are but brothers, escrito e realizado por Javaad Alipoor ${ }^{10}$, co-dirigido por Kirsty Housley e, nas suas palavras, uma palestraperformance, espécie de teatro documental. No trabalho de Alipoor, que é escritor, realizador e intérprete, percebemos uma dramaturgia-conferência que não separa texto, encenação, atuação ou reflexão crítica; ao contrário, ao colocar em cena temas e ideias caros à contemporaneidade, como masculinidade, identidade e o modo como a tecnologia está atuando sobre essas noções, chama nossa atenção para as estruturas e dispositivos de controle que constroem nossos afetos, as visões de mundo e, acima de tudo, as noções de "nós e eles", centro e margem, certo e errado. É importante observar que, como artista muçulmano, ao reivindicar a palavra, se posiciona como um agente epistemológico, como sujeito que constrói as hipóteses sobre a forma de produção do objeto discursivo, numa operação semelhante a que propôs Kilomba, já citada por nós, de transformação do "objeto" em "sujeito", caro ao projeto decolonial.

10 Javaad Alipoor é um artista, diretor, escritor e ativista asiático britânico baseado no norte da Inglaterra. Ele faz teatro com e para comunidades que normalmente não se dedicam às artes. O seu trabalho independente é formalmente desafiante e politicamente comprometido. 
Figura 2 - Javaad Alipoor in The Believers Are But Brothers. Foto: The Other Richard

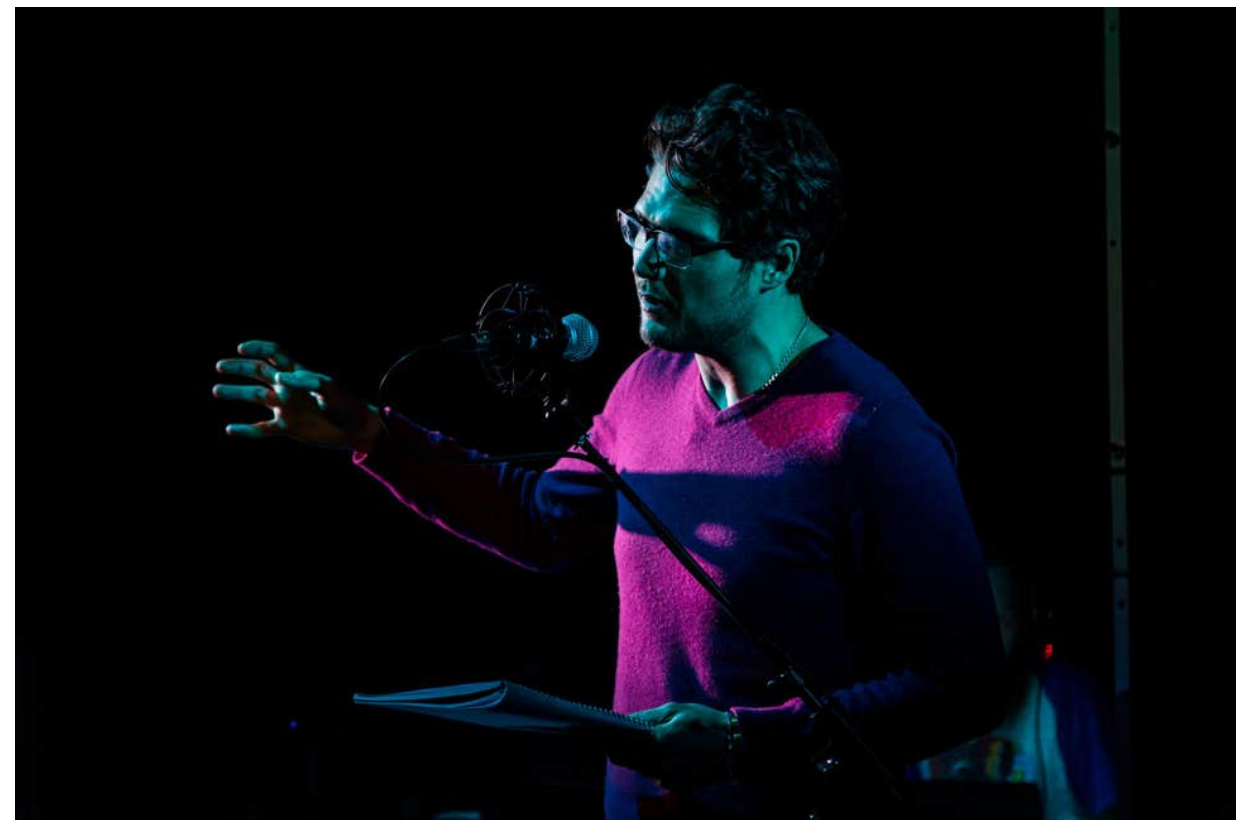

Fonte: In: https://www.ft.com/content/6b3d0e0c-05a8-11e8-9650-9c0ad2d7c5b5. Acesso em: 03 jul. 2020.

Jos Houben, ator belga e membro fundador do Théâtre Complicite, apresentou em 31 de outubro de 2007 sua practical lecture sobre A Arte do Riso. Dessa masterclass um dos ouvintes constatou que

é difícil definir exatamente qual o formato que esse maravilhoso evento adotou. Atrevo-me a dizer que foi uma aula sobre a arte da comédia pastelão, com performance ao vivo para informar o conteúdo. "Informar" talvez evoque a essência da peça de maneira errada: parecendo muito restrito ou sem graça. Se tratava de tudo, menos isso. Divertido, burlesco, esclarecedor, alegre seriam termos muito mais adequados ${ }^{11}$. (The Capital Centre, 2007, s/p).

Ou seja, o público que lotou estúdio sem saber definir o que assistiu, saiu com a sensação de ter aprendido algo, mas ao contrário de uma palestra ou uma aula convencional, esta curva de aprendizado não foi forçada. Essa passagem pela

${ }^{11}$ it's difficult to put your finger on precisely what format this wonderful event adopted. I'd venture to propose it was a lecture on the art of slapstick comedy with live performance to inform the content. 'Inform' perhaps conjures the wrong essence of the piece: it sounds too constricting or bland. This was anything but. Entertaining, amusing, enlightening and great fun would be terms far more apt. (The Capital Centre, 2007, s/p). (Tradução nossa) 
experiência de Jos Houben, reforça, da maneira como entendemos, mais uma característica da peça-conferência, qual seja, a instituição de momentos de reflexão, a construção de uma inteligência pública a partir de questões e olhares diversos, entre vários campos do pensamento, se tornando um espaço privilegiado do estranhamento e da desaprendizagem (Thürler, 2018), o que evidencia que as dramaturgias-conferências tem forte caráter interdisciplinar e se implicam nas discussões, valores e visões de mundo contemporâneas, como atesta Silvana Garcia (2009, p. 325):

Tematicamente, é vasto o panorama que se constituiu com as obras da nova geração. Não difere muito do que sempre serviu à dramaturgia como principais motivos: violência urbana, a falência de valores e perspectivas da sociedade, choque de gerações, incomunicabilidade e impotência do indivíduo acuado social e psicologicamente, etc. Essa revisão de temas já explorados pelas gerações anteriores, porém sob novos tratamentos, tanto no que se refere à linguagem, quanto pelos novos enfoques introduzidos, pode ser tomada como uma das características fortes de boa parte da dramaturgia produzida nos anos de 1980/1990. No geral, há uma acentuada recusa de padrões mais francamente realistas, ou realistas-psicológicos em favor de realismos contaminados pelo grotesco, pelo fantástico, pelo nonsense. Muitos autores incorporam elementos da desconstrução narrativa que caracteriza a contemporaneidade, e mesmo as peças curtas apresentam procedimentos de montagem e colagem como princípio de construção, bem como podem ser reconhecidas pelas referências a outras obras e autores, dando voz à polifonia intertextual. Os procedimentos metalinguísticos, que também definem a produção contemporânea, com frequência sobrepõem-se aos constituintes rigorosamente dramáticos que aí sobrevivem.

A peça-conferência, em sua clara estética anti-wagneriana, ao abandonar o ilusionismo teatral burguês se propõe em tom de conversa, a uma espécie de pensamento encenado com claro posicionamento à esquerda. Quando falamos dessa posicionalidade, apresentamos uma ideia de Deleuze, extraída de uma entrevista filmada nos anos 1988-1989. Nesse vídeo, Deleuze apresenta duas ideias importantes. A primeira, ao ser perguntado sobre o que é ser de esquerda, afirma que ser de esquerda seria se colocar num horizonte mais amplo de percepção, um olhar que abarca primeiro o mundo e a experiência coletiva, "é saber que os problemas do Terceiro Mundo estão mais próximos de nós do que os de nosso 
bairro" (Deleuze,1988/1989, s/p) e, assim, define a esquerda a partir de uma visão ampla de mundo que antecede qualquer individualismo. A segunda ideia que podemos retirar do vídeo é a associação da esquerda como um conjunto de minorias e nunca uma maioria hegemônica. Rita Von Hunty confirmaria essa tese, afinal

é impossível ser humano de direita. Ser humano é acreditar que, poxa, você também devia estar comendo, você devia ter acesso a todos os serviços. Não faz sentido que você receba dois centavos de dólar para fazer um Iphone. Até hoje eu tenho muita dificuldade de entender como algumas pessoas se definem de direita com orgulho. Porque historicamente é uma aberração. (Hunty, 2019, s/p).

\section{Algumas ressonâncias}

Este novo cenário provocou uma "explosão sem precedentes de criatividade que atingiu o conjunto do fenômeno teatral" (Kinas, 2010, p. 181) nos últimos anos, abrindo caminho para uma série de produções brasileiras semelhantes às anteriores, como Mortos-Vivos - Uma Ex-Conferência (2017), da Companhia Teatral Foguetes Maravilha e Colônia (2017), monólogo com Renato Livera e direção de Vinicius Arneiro, a partir do Livro Holocausto Brasileiro, de Daniela Arbex, com dramaturgia de Gustavo Colombini.

Figura 3 - Renato Livera, em Colônia

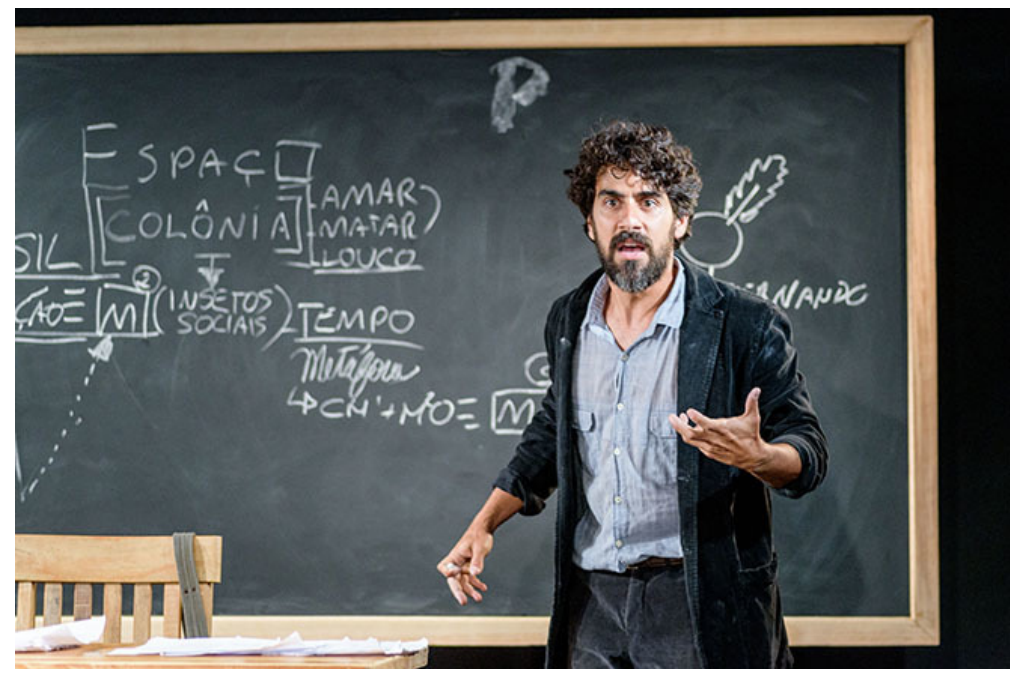

Fonte: https://renatolivera.com/colonia. Acesso em: 03 jul. 2020 
Mortos-Vivos - Uma Ex-Conferência, por exemplo, parte de uma premissa cômica e fantasiosa, um apocalipse zumbi, para tratar das mazelas sociais, como alteridade, xenofobia, fascismo, preconceito, tortura, a banalidade do mal, o fascínio pela violência. Colônia, mais do que um relato sobre a loucura e a condição dos internos no extinto manicômio Colônia, em Barbacena (MG), passa por várias acepções da palavra "colônia”, mas foca em especial na formulação da noção de colonialidade, elucidando os desdobramentos sociopolíticos desse processo, como algo que transcende as particularidades do colonialismo histórico e que não desaparece com a independência ou descolonização (Quijano,1997). Nessa perspectiva, as mazelas sociais, a intolerância, desafeto e violência notadas em Mortos-Vivos - Uma Ex-Conferência, podem ser lidas como resultado da colonialidade, das antigas hierarquias coloniais agrupadas na relação europeu versus não europeu, encenados em Colônia.

E é assim, nesse formato híbrido, entre drama e não drama, narração e interpretação, realidade e ficção que a cena contemporânea vem unindo a poética à política como uma resposta ao conturbado clima social e político em que vivemos nos últimos tempos. O formato dessas encenações dá sinais claros de uma tendência recente do teatro brasileiro, como ainda é o caso de Versão Demo", escrita e protagonizada pelo ator e dramaturgo Tairone Vale, com direção de Rodrigo Portella, intitulada como peça-conferência; a aula_performance, em Cérebro_Coração, escrita e interpretada por Mariana Lima; a aula-conferência filosófica de Georgette Fadel, em Afinação / que, além de interpretar, assina a dramaturgia e a direção do espetáculo; e 3 maneiras de tocar no assunto, de Leonardo Netto, com direção de Fabiano de Freitas.

O que marca as dramaturgias citadas acima é sua construção rizomática (Conceição, 2016), devido à sua complexidade e o diálogo com uma variedade de gêneros literários e linguagens artísticas, bem como diferentes autores. Fadel, por exemplo, traz trechos de obras de pensadores como o dramaturgo Bertolt Brecht e dos filósofos Karl Marx e Georg Hegel; Mariana Lima inclui citações de Marcel Proust, além de inspirações visuais de Leonilson e de descrições cirúrgicas, como a retirada de um edema e revela: 
Eu não escrevi esses pensamentos sozinha. Foi uma escrita atravessada por escritos e memórias dos outros. Autores e autoras que me formaram e transformaram. E então veio a escrita no ar da sala de ensaio. No corpo. Primeiro com Isabel Teixeira, depois Renato e Kike, coautores do trabalho. As aulas de Paola Barreto, Luisa Duarte, Ricardo Krause e Helena Martins trouxeram todo um corpo de pensamentos, derivações, pulsões e acontecimentos que estão aí, nessa peça-aula ou conferênciaperformática. (Lima, 2018, s/p).

Dessa forma, é em direção a uma ótica rizomática, pós-dramática e performativa que se dará a escrita dessas "dramaturgias monstruosas”, que é como temos chamado um conjunto de dramaturgias que se mostra "contrário ao que é habitual" (Zanon, 2018, p. 39), ligado à reivindicação da individualidade fora dos moldes e regras rígidas da normalidade, dos convencionalismos sociais e culturais e, assim como os movimentos feministas promoveram o questionamento do que se acreditava ser uma "invenção da natureza" (Segato, 2018, p. 25), a "dramaturgia monstruosa" também reflete sobre normas, normalidade e normalização questionando, por exemplo, nosso cistema binário sexo-gênero e a suposta naturalidade dos sexos, propondo expandir o olhar para as infinitas possibilidades de ser.

É nesse diapasão que Leonardo Netto escreve e protagoniza o manifesto artístico 3 Maneiras de Tocar no Assunto (2019), peça que esteve em cartaz em Rio de Janeiro e São Paulo. Nesta aula, verdadeira ferramenta política emancipatória, Netto reúne três textos curtos: O homem de uniforme escolar, O homem com a pedra na mão e O homem no Congresso Nacional para discutir, por diferentes ângulos - a escola, a lei e o estado - a questão da homofobia em nossa sociedade, essa hostilidade provocada por uma forma específica de orientação sexual, a homossexualidade, esse

crime abominável, amor pecaminoso, tendência perversa, prática infame, paixão abjeta, pecado contra a natureza, vício de Sodoma: tantas designações que durante séculos serviram para qualificar o desejo e as relações sexuais ou afetivas entre pessoas do mesmo sexo. Relegado ao papel de marginal ou excêntrico, o homossexual é tido pela norma social como bizarro, estranho ou disparatado. Como o mal sempre vem de fora, na França, por exemplo, qualificou-se a homossexualidade de "vício italiano", "costume árabe", "vício grego" ou, ainda, "costume colonial". O 
homossexual, assim como o negro, o judeu ou o estrangeiro, é sempre o outro, o diferente, aquele com o qual qualquer identificação é impensável. (Borrilo, 2009, p.15-16).

Na primeira cena, O homem de uniforme escolar, construído através de histórias verídicas de jovens e crianças que sofreram com a discriminação, vemos cenas cruéis de bullying homofóbico, uma prática social que marca o cotidiano das escolas de ontem e de hoje, e tudo o que é preciso para entender e praticálo com perfeição, uma espécie de engrenagem da crueldade que opera na desqualificação do outro, do diferente e nos convoca a "nos posicionar, a (re)agir, a abandonar a 'confortável' posição de indiferença ou mesmo de apatia" (Pessoa, 2019, s/p), afinal, como podemos não nos espantar com a homofobia

que mata todo mundo: o pai, que teve a orelha arrancada, por beijar o filho; os irmãos, que foram linchados, por andarem abraçados. Não adianta achar que você está livre, porque você não é 'gay'. Estamos vivendo um retrocesso de entendimento sobre isso, um conservadorismo estúpido. A população LGBT, no Brasil, está alijada de quase setenta direitos previstos na Constituição. (Bartholo, 2019, s/p).

A segunda cena se baseia num fato real, a Revolta de Stonewall em 28 de junho de 1969, "evento que se tornou um marco da luta por igualdade de direitos civis e introduziu definitivamente na agenda política a questão dos direitos sexuais para gays, lésbicas, bissexuais, travestis e transexuais" (Pelúcio, 2011, p. 111), e quem nos conta a história é um dos frequentadores do bar e que participou da noite de revoltas. É pela sua lente, seu olhar fresco que nos transporta para o bar "Stonewall Inn", em Nova Iorque.

Por fim, Netto encena O homem no Congresso Nacional, no qual constrói dramaturgia baseada nas falas e discursos do ex-deputado federal Jean Wyllys proferidos entre 2011 e 2018, antes de auto exilar-se.

O que parece unir as três cenas, além da dimensão social e política da sexualidade que permanece às margens, é a "experiência da vergonha", 
ser chamado, leia-se, ser xingado de bicha, gay, sapatão, travesti, anormal ou degenerad@ é a experiência fundadora da descoberta da homossexualidade ou do que nossa sociedade ainda atribui a ela, o espaço da humilhação e do sofrimento. Transformar esta experiência em força política de resistência é o objetivo da proposta original queer. (Miskolci, 2011, p. 48).

Figura 4 - Leonardo Netto na última cena da peça. Foto: Juliana Chalita

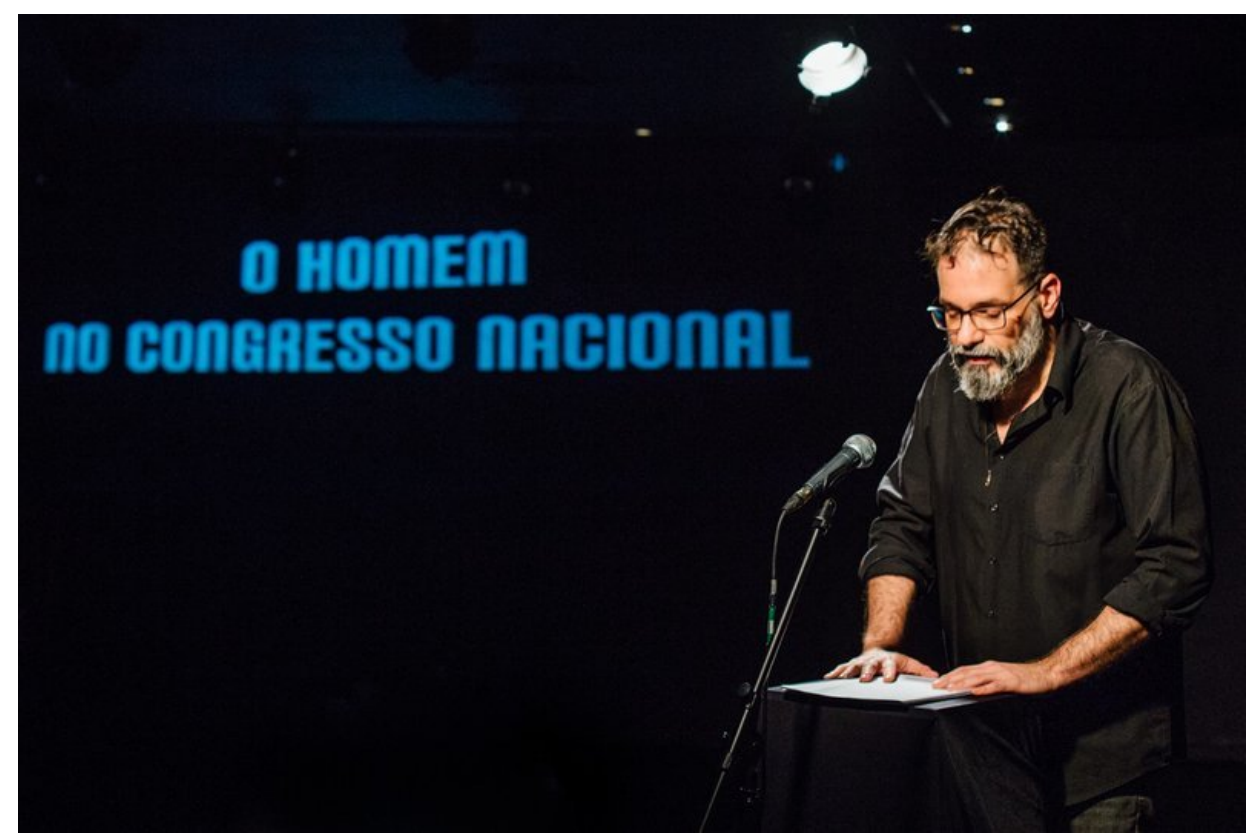

Fonte: https://www.vakinha.com.br/vaquinha/3-maneiras-de-tocar-no-assunto. Acesso em: 03 jul. 2020.

Versão Demo (2019), propõe contar a história da Bíblia, mas com uma narrativa a partir do olhar do Diabo e nos faz repensar a figura divina concebida à imagem e semelhança do homem branco, cisgênero, produto de um sistema patriarcal segregador, controlador e autoritário. Para o dramaturgo e também ator Tairone Vale, que pesquisou como o Diabo é citado na Bíblia e em outras mitologias, sua representação, também, como um homem branco é importante para abrir um leque de questionamentos sobre hegemonias que insistem em existir, nesse caso, em especial, sobre a branquitude como identidade racial normativa. Ainda segundo o autor, "a peça fala de opressão e debate sobre a quantidade de absurdos que estamos vivendo hoje em dia" (Rocha, 2019, s/p). 
Assim, o demônio-professor - "o demônio, ninguém é mais queer do que ele" (Silva, 2013, s/p) - vai assumindo seu papel queer, o de questionar a normalidade, a aparente naturalidade das coisas e relações, "as cumplicidades com narrativas heterossexuais e coloniais dominantes" (Preciado, 2017, s/p) e, com esse contra discurso, vai provocando pílulas de reflexão e crítica sobre várias camadas de opressão existentes na sociedade, afinal, como pensou Sam Bourcier, "é impossível fazer uma arte queer sem ir contra o neoliberalismo." (Bourcier, 2015, p. 01).

Um demônio-queer que desconstrói a representatividade do mal a partir do seu ponto de vista, a sua versão da estória, uma história coral em que a fábula principal é atravessada por dramaturgias paralelas, como citações de políticos, pastores, poetas, além de músicas, manchetes e a carta de um assassino, conectando a história narrada pelo diabo ao atual momento político e social da humanidade. A encenação consonante com a estética de uma peça-conferência, busca construir um espaço característico de uma palestra: microfones, retroprojetor, equipamentos de som e luzes, porém, todo o aparato tecnológico é operado pelo ator.

Cérebro_Coração parte do paradoxo vivido pela atriz Mariana Lima, que "convivia com a exuberância de uma vida nascendo e o terror de uma criança morrendo. Aquilo gerou um curto-circuito na minha cabeça" (Folha de São Paulo E, 2018, s/p). O texto é resultado de um processo de escrita conjunta, de textos recortados, leituras e vivências da atriz Mariana Lima em parceria com os diretores Renato Linhares e Enrique Diaz. De modo geral questiona a colonialidade do saber, colocando em perspectiva os modos de aprendizagem, a sensibilização e o entendimento científico-poético do mundo, retorcido por transfigurações da própria linguagem, da experiência cênica e do corpo, esse esqueleto adormecido nas narrativas e, ao mesmo tempo, tão responsável por nos manter de pé. 


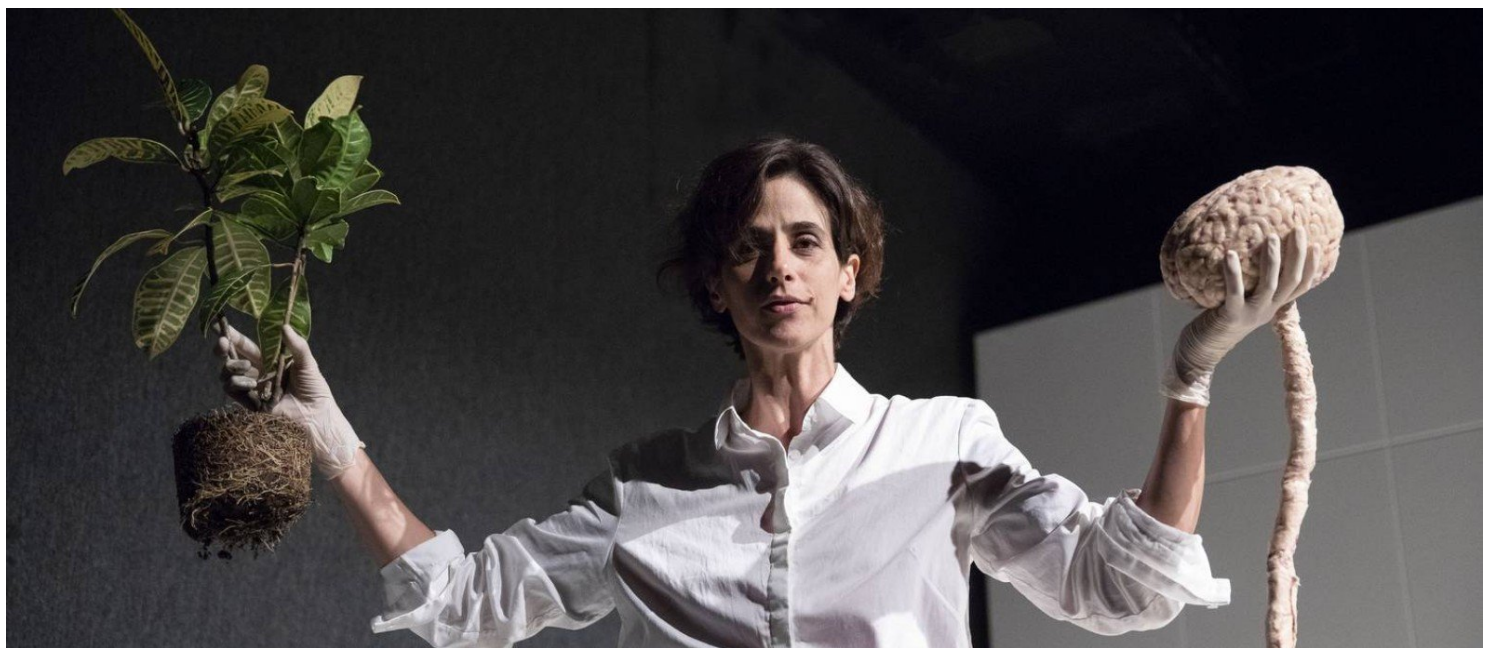

Fonte: http://verbenacomunicacao.blogspot.com/2018/08/mariana-lima-encena-cerebrocoracaono.html. cesso em: 03 jul. 2020

No material de divulgação da peça, ficamos sabendo que durante o período de ensaios, o espetáculo foi apresentado para alunos do Ensino Médio em algumas escolas da Rede Estadual do Rio de Janeiro, nas cidades de São João de Meriti e Nova Iguaçu, em salas de aula mesmo, sem nenhuma maquiagem cênica, fato que revela importante característica desta estética, o apagamento da fronteira entre o teatro e a sala de aula:

Em alguns casos, os alunos acharam que era uma aula de verdade, foi muito bonito. Viram ali uma cientista falando de cérebro, de neurologia. Só acharam que era uma aula diferente, onde estavam sendo convidados para fechar os olhos e olhar para dentro. (Lima, 2019, s/p).

Afinação / (2017) se aproxima ainda mais de uma sala de aula, ao menos foi essa a disposição cênica quando estreou em um pequeno auditório e cadeiras para 30 pessoas no SESC Ipiranga, em São Paulo. Nesse espetáculo, Georgette Fadel é a própria pensadora e professora francesa Simone Weil, a guardiã do pensamento, e estabelece, desde o início, que se trata de uma peça-conferência, tanto que todos são convidados a pegar pranchetas e canetas para as devidas anotações da aula. 
A peça é carregada de elementos de uma peça-conferência, a começar pelo cenário, composto apenas de uma cadeira e uma pequena mesa a sua frente (com xícara de café, uma garrafa térmica e um copo de água), com pouquíssimas variações de luz e a ausência de trilha sonora: "Eu não quis nem mesmo trilha sonora ou qualquer outro elemento que pudesse roubar a nossa atenção. Tem que ser tão agradável que o público pode levantar a mão e participar, se quiser”. (Fadel, 2017b, s/p).

Usando a personagem central da peça de Brecht, Santa Joana dos Matadouros, a professora fala da relação entre a opressão e o sofrimento no mundo:

os textos, reunidos em 'Afinação', trazem uma reflexão sobre como estamos distantes da razão, sobre como vivemos a supervalorização do sentimento individual, das paixões, opiniões e convicções que não nos unem, em detrimento do pensamento racional que nos liberta. (Fadel, 2017a, s/p).

A professora, que começa sua aula tendo um violoncelo como suporte de suas falas, pede ajuda a um dos alunos-espectadores para que escreva no quadro alguns dos conceitos centrais da conferência e passa, a partir de então, a interagir com os outros alunos/espectadores. Importa dizer que a presença do violoncelo em cena não é para a execução de uma trilha sonora, como dissemos anteriormente, ela não existe:

Faço uma brincadeira, fico sentada como se fosse uma professora com seus alunos e meu mote de brincadeira cênica é o violoncelo, que simboliza uma tentativa de afinação de pensamento. Brinco com ele em alguns momentos e crio, de uma maneira lúdica, essa sensação de estar buscando a verdade, a afinação do pensamento e a afinação do violoncelo. É uma maneira de tornar realmente cênica a palavra e a comunicação. (Maciel, 2017, s/p).

Os textos dos filósofos discutidos na peça-conferência - da própria Simone Weil, acrescidos de trechos de obras de outros pensadores como o dramaturgo Bertolt Brecht e dos filósofos Karl Marx e Georg Hegel - são de extrema complexidade, mas, no fundo, buscam dar o protagonismo ao pensamento e 
fazem uma defesa: 1) da ciência enquanto liberdade, afinal todos esses autores, "defenderam o pensamento racional como uma visão de mundo, para que a gente aprenda a não reagir com base nas emoções. A razão surge como uma força contra os que querem nos enganar, impedindo oportunidades de opressão" (Fadel, 2017b, s/p) e, por que não, da valorização dos professores no Brasil e de sua importância na sociedade, frente à patrulha ideológica de guerrilhas virtuais e de pais dos estudantes, que só começava em 2017, ano em que o espetáculo estreou.

Em comum, Afinação / e Cérebro_Coração valorizam tanto professores como a sala de aula como elementos potentes de desaprendizagem e liberdade. Para Fadel, os professores "são como contadores de histórias. Eles são os responsáveis por provocar em nós o desejo de buscar o conhecimento. É uma maneira de mostrar como a sala de aula é importante e necessária" (Fadel, 2017b, s/p). Para Mariana Lima, tanto o teatro como a sala de aula são lugares de transformação e de troca, onde você nunca sai da mesma forma que entrou:

Não tenho desejos e inclinações messiânicas, de querer expor a minha verdade. O espetáculo é mais um compartilhamento de perguntas do que de respostas. Tem mais a ver com expor a falha do que expor certezas e pensamentos bem-acabados". (Lima, 2018, s/p).

Fadel e Lima, em uníssono, acreditam que é preciso construir novos pensamentos e novas visões do outro e a sala de aula é a "estratégia micropolítica que precisamos" (Fadel, 2017c, s/p):

\footnotetext{
Escrevo esse texto duas semanas antes da peça estrear no teatro, já tendo passado por algumas escolas estaduais. Essa foi a experiência que sempre desejei ter, fazer esse texto para alunos, antes de fazer no teatro. Está sendo transformador, potente e muito amoroso cruzar a linha que separa esses mundos, linha absurda, inacreditável. Por que não estamos fazendo teatro nas escolas, passando filmes nas escolas? Estamos cada vez mais fechados dentro de caixas que nos separam. Por quê? (Lima, 2017b, s/p).
}

Outrossim, se as peças-conferências encontram na sala de aula lugar experimental por excelência é, também nesse espaço que elas reforçam seu caráter cultural e político interdisciplinar, as relações de poder e de forças 
implicadas nos processos de produção de subjetividades subalternas e não normativas,

portanto, falar de subjetividade é falar de uma maquínica, de um processo de produção dirigido à geração de modos de existências, ou seja, modos de agir, de sentir, de dizer o mundo. É analisar um processo de produção que tem a si mesmo, o sujeito, como produto. (Tedesco, 2006, p.358).

Assim, lembrados por Tedesco, Lima e Fadel, interessadas nas relações de produção política contra-pedagógica, se implicam pessoalmente na construção de processos de subjetivação não hegemônicos e, se como dissemos no começo desse estudo, a arte como potência de si transforma o "objeto" em "sujeito", isso se faz em boa medida porque a peça-conferência, ao articular temas e questões entre o teatro e a sociedade, estabelece contato com diferentes saberes, além de uma escuta potente dos fenômenos sociais e políticos emergentes, tentando estabelecer brechas e diálogos transformadores e críticos através de políticas da diferença.

Desse modo, tanto Mariana Lima quanto Georgete Fadel, realizam suas aulas na encruzilhada entre os estudos da subjetividade e o pensamento contemporâneo em teatro, como uma experiência de desconstrução coletiva de práticas sociais normativas, uma espécie de contra-pedagogía de la crueldad,

una contra-pedagogía del poder y, por lo tanto, una contra-pedagogía del patriarcado, porque ella se contrapone a los elementos distintivos del orden patriarcal: mandato de masculinidad, corporativismo masculino, baja empatía, crueldad, insensibilidad, burocratismo, distanciamiento, tecnocracia, formalidad, universalidad, desarraigo, desensitización, limitada vincularidad. (Segato, 2018, p.15).

\section{Conclusão}

Em última instância, a peça-conferência possibilita um lugar distinto de enunciação, de desconstrução e de projeção de um projeto ético que pensa esse tipo de montagem cênica como um potente instrumento de crítica da 
normalização biopolítica do Estado (Miskolci, 2012) e a envolver a diferença como fundamento político que interrogue o vasto mapa da normalidade.

Ademais, apesar das semelhanças, é preciso afirmar que, diferente de uma aula convencional onde improvisação e presença de espírito são fatores importantes, a peça-conferência, enquanto instância pública do discurso reflexivo, é ensaiada exatamente como uma peça de teatro, mas, ao invés de perseguir o drama diegético, se concentra em sua não-dramaticidade, quer seja na impossibilidade de agir das personagens, quer seja na desconstrução das noções de ação, tempo e espaço, quer seja na “ode ao pensamento”. (Fadel, 2017c, s/p).

E, por fim, a peça-conferência e todas as suas variações marcam, definitivamente, um novíssimo ator na cena contemporânea. Percebam que, além de atuar, Georgette Fadel assina a dramaturgia e a direção do espetáculo, que sem dúvida é inusitado em sua forma e na maneira de conduzir a trama. Mariana Lima concebe a ideia de Cérebro_Coração, além de ter escrito e atuado. Tairone Vale, ator juiz-forano, e Leonardo Netto, assim como Mariana Lima tiveram a ideia e foram autores e atores solo de Versão Demo e 3 maneiras de tocar no assunto, respectivamente.

Há nesses atores e atrizes algo de diferente quando valorizam o discurso, experimentam o seu pensamento e experimentam o pensamento do outro, tudo em detrimento de elementos espetaculares da cena. Atores intelectuais que, ao atribuírem ao anti-intelectualismo um projeto protofascista, experimentam e elaboram o pensamento em frente à plateia, fazendo com que seu alunoespectador, de forma socrática, chegue, por si mesmo a algo novo, não importa o quê, "evidenciando o caráter arbitrário da cultura, a [nenhuma] universalidade das regras, a total contingência das coisas e, com isso, criticar a naturalidade e a normalidade dos hábitos que se tornam natureza. Criticar a ideia de natureza” (Hansen, 209, p. 116-117), fazê-los compreender que tudo o que acreditava ser verdade, não passa apenas de uma aparência de verdade, que a "ficção é prática simbólica do real, social e histórica" (Hansen, 2019, p.119). Estamos falando de um ator-epistemólogo, que compreende a cena como um tecido de relações 
intersubjetivas, uma matéria em movimento, uma prática presente que atua sobre o presente.

\section{Referências}

BARTHOLO, Gilberto. 3 Maneiras de Tocar no Assunto' - E muito mais que três motivos para se assistir ao espetáculo. Disponível em: https://rioencena.com/3maneiras-de-tocar-no-assunto-e-muito-mais-que-tres-motivos-para-seassistir-ao-espetaculo/. Acesso em 12 abr. 2020.

BORRILO, Daniel. Homofobia. In: Homofobia \& Educação: um desafio ao silêncio. (Org.) Tatiana Lionço; Debora Diniz (Organizadoras). Brasília: LetrasLivres: EdUnB, 2009.

BOURCIER, Sam. Entrevista a Pedro Paulo Gomes Pereira. Revista Cult, São Paulo, Editora Bregantini, n.205, setembro 2015. p.11-15.

BRECHT, Bertolt. Teatro Dialético. Rio de Janeiro: Brasileira, 1967.

CATALÃO, Marco. Uma genealogia para a palestra-performance. Urdimento Revista de Estudos em Artes Cênicas, Florianópolis, v.1, n.28, p. 4-14, 2017.

CONCEIÇÃO, Jorge Wilson da. Distinções polifônicas na dramaturgia contemporânea: em cena a escrita colaborativa do Grupo XIX de Teatro. São Paulo. 2016. (Tese). Programa de Estudos Pós-graduados em Letras da Universidade Presbiteriana Mackenzie.

DELEUZE, G. O que é ser de esquerda. Disponível em: https://www.facebook.com/watch/?v=5979806103417941988-1989. Acesso em: 08 maio 2020.

EPPS, Philomena. Xavier Le Roy, Product of Circumstances 2009. Case study, Performance At Tate: Into the Space of Art, Tate Research Publication, 2016. Disponível em: https://www.tate.org.uk/research/publications/performance-attate/case-studies/xavier-le-roy. Acesso em: 9 jun. 2020.

FADEL, Georgette. Georgette Fadel Estreia Afinação-Ajuste. Flertaí, 2017a. Disponível em: http://flertai.com.br/2017/05/georgette-fadel-estreia-afinacaoajuste/. Acesso em: 08 jun. 2020.

FADEL, Georgette. Georgette Fadel invoca clima de sala de aula em 'Afinação I'. Reviste Isto é, 13/01/17. 2017b Disponível em: https://istoe.com.br/georgette-fadelinvoca-clima-de-sala-de-aula-em-afinacao-i/. Acesso em: 08 jun. 2020. 
FADEL, Georgette. Peça com Georgette Fadel transforma o teatro em "sala de aula". 12/09/2017. GZH. 2017c. Disponível em: https://gauchazh.clicrbs.com.br/cultura-elazer/espetaculos/noticia/2017/09/peca-com-georgette-fadel-transforma-oteatro-em-sala-de-aula-9896078.html. Acesso. em: 08 jun. 2020.

FERRER, Maria Clara. O desempenho da escuridão. Revista Sala Preta. São Paulo, Vol. 14. n. 2, 2015.

FOLHA DE SÃO PAULO. Montagem curitibana de obra de Denis Guénoun estréia hoje. "Carta Aberta" propõe reflexão sobre o teatro. 03/082019. Disponível em: https://www1.folha.uol.com.br/fsp/acontece/ac0308200001.htm. Acesso em: 12 mar. 2020.

FOLHA DE SÃO PAULO. Atriz camaleônica, Mariana Lima se divide entre emoção e razão em peças e filmes. 21/08/2018. Disponivel em: https://www1.folha.uol.com.br/ilustrada/2018/08/atriz-camaleonica-marianalima-se-divide-entre-emocao-e-razao-em-pecas-e-filmes.shtml. Acesso em: 12 mar. 2020.

FOUCAULT, Michel. Em defesa da sociedade: curso no Collège de France (19751976). Trad. Maria Ermantina Galvão. São Paulo: Martins fontes, 1999.

GARCIA, Silvana. A dramaturgia dos anos 1980/1990 In: GUINSBURG, J., FARIA, João Roberto e LIMA, Mariângela Alves de (Coord.). Dicionário do teatro brasileiro: temas, formas e conceitos. 2. ed. rev. e ampl. São Paulo: Perspectiva: Edições SESC SP, 2009.

GUZMÁN, Boris Ramírez. Colonialidad e cis-normatividade. Entrevista con Viviane Vergueiro. Disponível em: https://iberoamericasocial.com/wpcontent/uploads/2015/01/Ram\%C3\%ADrez-B.-2014.-Colonialidad-e-cisnormatividade.-Entrevista-con-Viviane-Vergueiro..pdf. Acesso em: 12 mar. 2020.

HANTY, Rita Von. Pode um professor ser Drag Queen? 2019. (07m51s). Disponível em: $\quad$ https://www.youtube.com/watch?V=4X44M45hDyU\&feature=emb logo. Acesso em: 13 maio 2020.

HANSEN, João Adolfo. Arte da Aula. In: CORDEIRO, Denilson Soares; FURTADO, Joaci Pereira (Org.). São Paulo: Edições SESC São Paulo, 2019.

KILOMBA, Grada. Memórias de plantação - Episódios de racismo cotidiano. Trad. Jess Oliveira. Rio de Janeiro: Cobogó, 2019.

KINAS, Fernando César. O lugar da ficção. São Paulo; Paris, 2010. (Tese) Departamento de Artes Cênicas da Universidade de São Paulo; École doctorale Arts et Médias, Université Sorbonne Nouvelle. 
LE ROY, Xavier. Score for the Product of Circumstances, 1999. Disponivel em: http://www.xavierleroy.com/page.php?id=63e83a12f776477d633187bdfbdb1c24c13 Oda87\&lg=en. Acesso em: 13 abr. 2020.

LIMA, Mariana. Cérebro_Coração. 2018. Disponível em: https://esquemanovo.com.br/eventos/cerebro coracao/. Acesso: 08 um. 2020.

LIMA, Mariana. Mariana Lima encena Cérebro_Coração no Sesc Piracicaba. Jornal de Piracicaba. 2019. Disponível em: https://www.jornaldepiracicaba.com.br/mariana-lima-encena-cerebro coracaono-sesc-piracicaba/. Acesso em: 08 jun. 2020.

LOURO, G. L. 2010. Pedagogia da sexualidade. In LOURO, G. L. (Org.). O corpo educado: Pedagogias da sexualidade. Belo Horizonte: Autêntica.

MACIEL, Nahima. Georgette Fadel traz monólogo sobre opressão para o Cena Contemporânea. Correio Braziliense. 2017. Disponível em: https://www.correiobraziliense.com.br/app/noticia/diversao-earte/2017/08/30/interna diversao arte,621819/georgette-fadel-monologoafinacao.shtml. Acesso em: 08 jun. 2020.

MISKOLCI, Richard. Não somos, queremos: notas sobre o declínio do essencialismo estratégico. In: Stonewall 40 + o que no Brasil? Leandro Colling (Org.). Salvador: EDUFBA, 2011.

MISKOLCI, Richard. Teoria queer: um aprendizado pelas diferenças. Belo Horizonte: Autêntica: UFOP - Universidade de Ouro Preto, 2012.

PESSOA, Patrick. Crítica: 3 maneiras de tocar no assunto. Jornal O Globo, 10/10/2019. Disponível em: https://oglobo.globo.com/rioshow/critica-3-maneirasde-tocar-no-assunto-24008935 Acesso em: 04 jun. 2020.

PELÚCIO, Larissa. É o que tem pra hoje - Os limites das categorias classificatórias e as possíveis novas subjetividades travestis. In: Stonewall 40 + o que no Brasil? Org. Leandro Colling. Salvador: EDUFBA, 2011.

PRECIADO, Paul B. Cartografias "queer": o "flâneur" perverso, a lésbica topofóbica e a puta multicartográfica, ou como fazer uma cartografia "zorra". Revista Performatus, Ano 5, n.17, 2017.

QUIJANO, Anibal. Colonialidade do poder, eurocentrismo e América Latina. In: LANDER, Edgardo (Org.). A colonialidade do saber: eurocentrismo e ciências sociais. Buenos Aires: Perspetivas latino-americanas CLACSO, 2005.

RANCIĖRE, Jacques. Política da arte. Disponível em: https://territoriosdefilosofia.wordpress.com/2014/05/30/politica- da-artejacques-ranciere/. 2014. Acesso em: 23 abr. 2020. 
ROCHA, Rafael. Tairone Vale apresenta o monólogo "Versão Demo" no Teatro Espanca! O ator juiz-forano faz sua estreia em Belo Horizonte com um trabalho que inspira-se nas representações da figura do Diabo. Jornal O tempo, 2019. Disponível em: https://www.otempo.com.br/diversao/tairone-vale-apresenta-omonologo-versao-demo-no-teatro-espanca-1.2182532. Acesso em: 08 jun. 2020.

ROLNIK, Suely. Esferas da insurreição - notas para uma vida não cafetinada. São Paulo: $n-1$ edições, 2018.

ROUBINE, Jean-Jacques. A Linguagem da Encenação Teatral. Rio de Janeiro: Ed. Jorge Zahar, 1998.

RYNGAERT, Jean-Pierre. Encarnar fantasmas que falam In: Revista Cena, Porto Alegre, n.6, 2008.

RYNGAERT, Jean-Pierre. Para ler o teatro contemporâneo. São Paulo, Ed: Martins Fontes, 2013.

SARRAZAC, Jean-Pierre. El impersonaje: Una relectura de La crisis del personaje. Literatura: teoría, historia, crítica, n.8, 2006.

SILVA, Tomás Tadeu da. Orelha do livro "Um corpo estranho - ensaios sobre sexualidade e teoria queer". Belo Horizonte: Autêntica Editora, 2013.

SEGATO, Rita. Contra-Pedagogías de la crueldade. Cidade Autônoma de Bienos Aires: Prometeo Libros, 2018.

SMALL, Daniele Avila. Para mastigar o teatro. Notas sobre o Fringe e o Edinburgh Showcase. British Council $2019 . \quad$ In: http://www.questaodecritica.com.br/2019/11/fringe2019/. Acesso em: 24 maio 2020.

TEDESCO, Silvia. As práticas do dizer e os processos de subjetivação. Interação em Psicologia, v.10, n.2, p. 357-362, 2006.

The CAPITAL Centre. The Art of Laughter with Jos Houben. The University of WarWick, 2007.2 Disponível em: https://warwick.ac.uk/fac/cross fac/capital/teaching and learning/learning event s/masterclasses/jos/. Acesso em: 25 mar.2020.

THÜRLER, Djalma. "Sabedoria é desaprender" - notas para a construção de uma política cultural das margens. SILVA, Gimima, PUGA, Lúcia, RIOS, Otávio (Org.). In: Alfabetização política, relações de poder e cidadania: perspectivas interdisciplinares. Rio de Janeiro: Letra Capital, 2018. 
THÜRLER, Djalma. Cabaré Vibrátil. Texto do espetáculo homônimo. Salvador: Cópia digital, 2019.

ZANON, Camila Aline. Ondem vivem os monstros. Criaturas prodigiosas na poesia de Homero e Hesíodo. São Paulo: Humanitas, 2018.

Recebido em: 11/06/2020

Aprovado em: 03/07/2020 